\title{
The cognitive reserve at the dementia with impaired eating behavior and apathy
}

\author{
Alena Sidenkova \\ Ural State Medical University. \\ Russia. Ekaterinburg \\ sidenkovs@mail.ru
}




\section{The relevance of the research}

- Eating disorders in late dementia are recognized as one of the most frequent phenomena with the occurrence to $40,8 \%$ of all cases of later dementia.

- They significantly contribute to the burden on the caregiver and can affect the overall condition of the elderly patient. No systematic data about eating disorders in later dementia. 


\section{The relevance of the research}

- A prospective observational comparative dynamic research was conducted on the basis of the Sverdlovsk regional clinical psychiatric hospital in $2011-2017$.

- To study the clinical symptoms and the dynamics of dementia with disorders of eating behaviour and dementia with normal eating behavior. 


\section{Research methods}

- Clinical

- Psychopathological

- Psychometric

- Neuropsychological

- Statistic 


\section{Research instruments}

- «Mini - Mental State Examination» (MMSE),

- «Neuropsychiatric Inventory» (NPI)

- «Alzheimer's Disease Cooperative Study

Activities of Daily Living Inventory» (ADCS ADL) 


\section{Research materials}

156 patients with later dementia both sex by age 60 and over with somatic and neurological condition on 0,5 months and over:

The key group - 106 patients with eating

disorders: 15 males and 91 females, age 79,0

$(73,0 \div 83,25)$ years

The comparison group: 9 males and 41 females, age $80,0(75,75 \div 83,0)$. 


\section{CONCLUSIONS}

1. Premorbid disorders of adult personality and behavior are more common in study participants with eating disorders $(p=0,033)$;

2.The earlier the onset of cognitive decline are more common in study participants with eating disorders $(p=0,01)$;

3. A t o t a li $m p$ a i $m$ e $n t$ of neuropsychological functions occurs more frequently than with dementia with intact feeding behavior $(\mathrm{p}>0,05)$;

4. There are often agitation/aggression $(p<0,001)$, a $p$ at $h$ y $(p=$ $0,027)$, irritability/emotional lability $(p=0,004)$ in dementia with eating disorders; anxiety in study participants intact eating behavior $(p=0,002)$;

5. The level of functional activity of patients with eating disorders is lower than in intact eating behavior $(p<0,001)$. 